strative staff to act contrary to his conscience," the association has failed to uphold the clear view of the profession. We understand that this is because it has been persuaded by members of the legal profession that expressions of advance wishes would be upheld at law. This, however, has not been tested in practice and is not accepted by some lawyers. In any case, advance directives should have been opposed as being incompatible with good medical practice and ethics rather than accepted as a fait accompli.

At the annual representative meeting it was inappropriate, especially for a matter of such grave importance, to conflate six motions expressing concern or even criticism of advance directives with two motions in favour of them so as to make a single, unwieldy motion (motion 470). Since a motion had just been passed to the effect that the matter had been inadequately discussed in the profession (469), and in view of the number of motions originally submitted and the number of would-be speakers, it is regrettable that no time was then found to debate motion 470 at all.

Bromley division believes that the following are important dangers of advance directives: developments in treatment cannot be accommodated; advance directives may prevent resuscitation in an emergency (this has happened) or even assessment over time to see whether the situation is reversible; survival after "non-treatment" may lead to a worse state than would have been the case if proper resuscitative measures had been carried out; doctors' hands are tied by a document that may require them to act contrary to informed medical opinion (and their consciences); and doctors and nurses, and their skills, effectively become redundant in such situations.

Medical staff tend to avoid those who spurn their best endeavours, and patients' care will suffer in consequence.

I M C D JESSIMAN

17 Grange Drive,

Chislehurst,

Kent BR7 5ES

\section{Doctors and medical politics}

\section{Electorate should be balloted on measures profoundly affecting clinical practice}

EDrToR,-The whingeing doctors of whom Douglas Carnall writes may stand on the sideline of medical politics, ${ }^{1}$ but they work in the front line of clinical practice, where the BMA and its various committees often seem a long way away. The actions of our political leaders become of real interest only when they result in that line being moved. We are, after all, registered as doctors and not politicians.

The letter criticising the new deal that Carnall cites (of which we were two of the signatories) was born out of feelings of frustration and impotence. ${ }^{2}$ We accept that we and our coauthors may be guilty of the apathy that Carnall identifies with regard to elections to the BMA's council. In this matter, however, we are a single issue, minority group Given the figures that Carnall provides, we could possibly secure representation on the council, but would this be good for the profession as a whole? It might be better to reduce the number of constituencies, so that those people who are genuinely interested have to compete for their posts, and to make it incumbent on them to ballot the electorate on measures, such as the new deal, that profoundly affect clinical practice. Any such ballot must take into account the heterogeneity of clinical medicine and identify the opinions of different groups within this. Our political leaders would then be equipped to represent not only the profession as a whole but also its various component parts. We would be happy to feel that we could devote our time and energy to our

vocation rather than whining and whingeing in the letters pages of the $B M Y$.

GRAHAM COOPER Senior registrar JAMES ROXBURGH Senior registrar

Department of Cardiothoracic Surgery, St Thomas's Hospital, London SE1 7EH

1 Carnall D. Doctors and medical politics. BMF 1995;311 1519-20. (9 December.)

2 Alhualifi $A$ and 64 others. New deal not satisfactory for cardiothoracic surgery. BMF 1995;311:953. (7 October.)

\section{BMA is meeting change with outraged} reaction rather than adaptation

EDrTOR,-Hooray for editorial registrars! Douglas Carnall has bravely tackled the fundamental problems facing representative organisations such

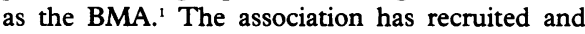
accredited a new nationwide echelon of local medical politicians numbering roughly 4000 , but the development of local negotiating committees may become a lost opportunity. Despite excellent work by officials in setting up and training local negotiators in industrial relations, media presentation, and negotiating skills, the central response to innovative local agreements has been derision, suppression, or attempted sabotage. Local negotiating committees are close to the members and their views but substantially remain outside the policymaking of their association, like judges making case law separate from statutory laws.

The association has yet to learn the difference between central control and local negotiation and remains ambivalent about the balance between local and central policymaking. There is indeed dissatisfaction among members with the representativeness of central craft committees and the realism of their edicts. Alas, the association is typically meeting the changed environment with outraged reaction rather than biological adaptation.

Despite the success of local medical politics, few local people will be inspired to seek national roles or would seem to be welcome if they did. The 15th century Venetian intrigues may be the very being of lifelong activists, but ordinary doctors can better find influential roles by entering the management of trusts locally than by getting on the 7 am train to London.

The BMA must reform itself to bring itself into the 20 th century if it is to reach the $21 \mathrm{st}$. We have a secretariat of great erudition and capability, local officials of immense practical skill and experience, and many new local politicians, yet we lie enchained by the shackles of Victorian organisational and representational architecture. A managerial revolution is afoot. We must also bring more active members into creative policymaking teams and do away with the annual coconut shy.

CARL CRAY ${ }^{\star}$ Consultant

Department of Histopathology,

Harrogate General Hospital,

Harrogate HG2 7ND

${ }^{\star}$ Carl Gray is the chairman of a BMA local negotiating committee and of the Harrogate division of the BMA.

1 Carnall D. Doctors and medical politics. $B M F$ 1995;311: 1519-20. (9 December.)

\section{Long term care can be provided by NHS at low cost}

EDrToR,-John Warden draws attention to the increasingly difficult problem of caring for elderly patients who need high dependency nursing care but not expensive hospital beds. ${ }^{1}$ One way in which good nursing home care can be provided at relatively low cost is by enlisting the voluntary sector. Experience in the Wirral shows that this can be achieved. The staff of the department of medicine for the elderly at Clatterbridge Hospital, headed by Dr John Aitken, thought of establishing an independent, non-profit making nursing home on the hospital campus to relieve pressure on hospital beds; active support came from the NHS at local and departmental levels, and the home opened in November 1989

The hospital authority built a nursing home with 49 individual rooms and leased it to a limited liability company with charitable status created for the purpose. Management was vested in a board of unpaid directors (local people actively interested in the care of elderly people, with wide experience in medical and other fields). It took some time to establish a competent management structure, which comprises a matron, an administrator, and a financial assistant. This made the home virtually able to run itself, with only policy decisions and advice in emergencies being required from the directors. This has worked well. The directors visit the home informally and develop areas of special interest in its affairs. A formal board meeting is held each month.

The objective has been to provide care for patients with low incomes on the basis of the support available from social services (currently $£ 295$ a week). We have shown that with careful budgeting an excellent service can be provided on this income alone. It is, however, vital for a home run on this basis to be as fully occupied as possible. Difficulties are that the local social services cannot fund all eligible patients and have, indeed, asked homes whether they can accept lower fees. Present information suggests that locally about 80 potential nursing home patients remain in hospital beds.

Our experience shows, firstly, that a useful element in solving the problem of long term care is to mobilise local interest and talent in the manner described; and, secondly, that the financing of such a scheme is imperilled if money from social services dries up, as is threatened in our case. The care of elderly patients needing nursing rather than hospital care would be facilitated if financed by the NHS rather than social services.

Chairman

Elderholme Nursing Home,

Clatterbridge Road,

Bebington,

Wirral L63 4JY

1 Warden J. Long term care pushed on to NHS. $B M F$ 1995;311 1454. (2 December.)

\section{Policies for humanitarian service should be less ageist}

EDrToR,-Peter Beale writes that colleges and trusts should show greater understanding towards medical staff who wish to do humanitarian work. 'I have just returned from Kurdistan in north Iraq, where I spent six weeks helping Emergency, an international organisation based in Milan, to set up and open a 50 bed surgical centre. When I retired from full time anaesthetic practice at the age of 63 I offered my services to the British Red Cross Society but was turned down as I was too old. I understand that other Red Cross societies do not have this age limit and that older doctors work with the International Committee of the Red Cross, but access to the international committee is through the national societies.

While in Kurdistan I celebrated my 74th birthday. I suggest that the British Red Cross Society should adopt a less ageist policy.

DE ROWLANDS

Plas Newydd,

Emeritus consultant anaesthetis

Penmolnawr,

1 Beale P. Colleges and trusts are blocking humanitarian service. $B M$ F 1995;311:1027. (14 October.) 